\title{
ПРАКТИЧЕСКИЕ РЕКОМЕНДАЦИИ ПО ЛЕКАРСТВЕННОМУ ЛЕЧЕНИЮ
} ЗЛОКАЧЕСТВЕННЫХ ТРОФОБЛАСТИЧЕСКИХ ОПУХОЛЕЙ

Коллектив авторов: Мещерякова Л.А., Карселадзе А.И., Кузнецов В.В., Мещеряков А.А., Чекалова М.А.

DOI: $10.18027 / 2224-5057-2020-10-3 s 2-15$

Ключевые слова: трофобластическая болезнь, злокачественные трофобластические опухоли, пузырный занос, персистирующие трофобластические опухоли, хориокарцинома,

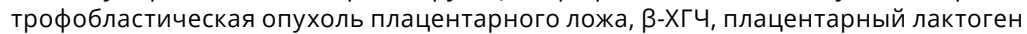

Злокачественные трофобластические опухоли (ЗТО) - уникальные опухоли человека, возникновение которых всегда ассоциировано с беременностью. ЗТО могут возникнуть как во время беременности, так и после ее завершения независимо от срока окончания беременности и ее исхода. Наиболее частым предшественником ЗТО является пузырный занос, в два раза реже искусственный и самопроизвольный аборт, затем - роды и эктопическая беременность. ЗТО поражают женщин преимущественно репродуктивного возраста, обладают очень высокой злокачественностью, быстрым отдаленным метастазированием и высокой чувствительностью к ХТ. Главным условием излечения абсолютного большинства больных ЗТО и сохранения у них репродуктивной функции является лечение в соответствии с современными стандартами в условиях высокопрофессионального медицинского учреждения, обладающего всеми диагностическими и терапевтическими возможностями и, главное,- успешным опытом лечения ЗТО.

\section{1. КЛАССИФИКАЦИЯ И ОПРЕДЕЛЕНИЕ СТАДИИ}

Для определения стадии ЗТО используется классификация ТМ (табл. 1) и объединенная классификация BO3 и FIGO (табл. 2), на основании которой планируется лечение.

Цитирование: Мещерякова Л.А., Карселадзе А.И., Кузнецов В.В., Мещеряков А.А., Чекалова М.А. Практические рекомендации по лекарственному лечению злокачественных трофобластических опухолей. Злокачественные опухоли: Практические рекомендации RUSSCO \#3s2, 2020 (том 10).15 
Таблица 1. Классификация трофобластических опухолей по ТМ

\begin{tabular}{|l|l|l|}
\hline TM & FIGO & Локализация опухоли \\
\hline Tx & & Первичная опухоль не может быть оценена \\
\hline T0 & & Первичная опухоль не определяется \\
\hline T1 & I & Опухоль в пределах матки \\
\hline T2 & II & $\begin{array}{l}\text { Опухоль распространяется на другие половые структуры: влагалище, яичник, широкую } \\
\text { связку матки, фаллопиеву трубу путем метастазирования или непосредственной инвазии }\end{array}$ \\
\hline M1а & III & Метастазы в легком (легких) \\
\hline M1b & IV & Другие отдаленные метастазы \\
\hline
\end{tabular}

Таблица 2. Классификация трофобластических опухолей (FIGO, 2003 г. и объединенная классификация FIGO и ВO3, 2000 г.)

\begin{tabular}{|c|c|c|c|c|c|}
\hline Стадия & \multicolumn{5}{|l|}{ Локализация новообразования } \\
\hline I & \multicolumn{5}{|l|}{ Болезнь ограничена маткой } \\
\hline II & \multicolumn{5}{|c|}{$\begin{array}{l}\text { Новообразование распространяется за пределы матки, но ограничено половыми органами } \\
\text { (придатки, широкая связка матки, влагалище) }\end{array}$} \\
\hline III & \multicolumn{5}{|c|}{ Метастазы в легких в сочетании или без поражения половых органов } \\
\hline IV & \multicolumn{5}{|l|}{ Другие метастазы } \\
\hline \multicolumn{6}{|c|}{ Определение риска развития резистентности к лекарственной терапии } \\
\hline \multirow{2}{*}{\multicolumn{2}{|c|}{ Параметры }} & \multicolumn{4}{|c|}{ Количество баллов } \\
\hline & & 0 & 1 & 2 & 4 \\
\hline \multicolumn{2}{|c|}{ Возраст (в годах) } & $<40$ лет & $>40$ лет & - & - \\
\hline \multicolumn{2}{|c|}{ Исход предшествующей беременности } & $\begin{array}{l}\text { Пузырный } \\
\text { занос }\end{array}$ & Аборт & Роды & \\
\hline \multicolumn{2}{|c|}{$\begin{array}{l}\text { Интервал между окончанием предыдущей } \\
\text { беременности и началом XТ }\end{array}$} & $<4$ мес. & 4-6 мес. & 7-12 мес. & $>12$ мес. \\
\hline \multicolumn{2}{|c|}{ 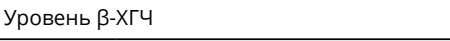 } & $<10^{3} \mathrm{ME} / \Omega^{1}$ & $10^{3}-10^{4} \mathrm{ME} / л$ & $10^{4}-10^{5} \mathrm{ME} / л$ & $>10^{5} \mathrm{ME} / л$ \\
\hline \multicolumn{2}{|c|}{$\begin{array}{l}\text { Наибольший размер опухоли, включая } \\
\text { опухоль матки }\end{array}$} & $<3 \mathrm{CM}$ & $3-5 \mathrm{~cm}$ & $>5 \mathrm{~cm}$ & \\
\hline \multicolumn{2}{|c|}{ Локализация метастазов } & Легкие & $\begin{array}{l}\text { Селезенка, } \\
\text { почка }\end{array}$ & Органы ЖКТ & $\begin{array}{l}\text { Печень, } \\
\text { головной } \\
\text { мозг }\end{array}$ \\
\hline \multicolumn{2}{|c|}{ Количество метастазов } & & $1-4$ & $5-8$ & $>8$ \\
\hline \multicolumn{2}{|c|}{ Предыдущая XT } & & & $\begin{array}{l}\text { Один пре- } \\
\text { парат }\end{array}$ & $\begin{array}{l}\text { Два или } \\
\text { более препа- } \\
\text { ратов }\end{array}$ \\
\hline
\end{tabular}

1 Низкий уровень $\beta$-ХГЧ может быть при трофобластической опухоли на месте плаченты 
Выделяют следующие гистологические варианты трофобластической болезни (FIGO, 2003 г.):

- пузырный занос $(9100 / 0)$

- полный пузырный занос $(9103 / 0)$

- частичный пузырный занос (9103/0)

- инвазивный пузырный занос $(9100 / 1)$

- метастатический пузырный занос (9100/1)

- хориокарцинома (9100/3)

- трофобластическая опухоль плацентарного ложа (9104/1)

- эпителиоидная трофобластическая опухоль (9105/3).

\section{2. ДИАГНОСТИКА}

Первым этапом в диагностике ЗТО является выявление жалоб, изучение акушерского анамнеза, оценка общего состояния больной и гинекологический осмотр.

\section{1. Жалобы}

Большинство женщин репродуктивного возраста предъявляют жалобы на нарушение менструального цикла (аменорею, ациклические кровяные выделения, олигоменорею, маточные кровотечения различной интенсивности и продолжительности). Более редкими являются жалобы на боли внизу живота, в грудной клетке, кашель, кровохарканье, головную боль, различные проявления токсикоза беременных, возможны явления тиреотоксикоза. В отдельных случаях пациентки самостоятельно обнаруживают метастазы во влагалище или опухоль в малом тазу, пальпируемую через переднюю брюшную стенку. Особое внимание следует уделить жалобам на рецидивирующие маточные кровотечения после родов, аборта, эктопической беременности.

\section{2. Акушерский анамнез}

Наиболее часто болезнь возникает у женщин репродуктивного возраста, хотя может развиться и у пациенток в перименопаузе. В анамнезе обязательно имеет место беременность, в том числе и эктопическая, завершенная родами, абортом (искусственным или самопроизвольным). Трофобластическая опухоль может возникнуть и в период развивающейся беременности, но чаще развивается после перенесенного пузырного заноса.

\section{3. Физикальное обследование}

- Гинекологический осмотр, забор цитологического материала с экто-и эндоцервикса: при гинекологическом осмотре можно обнаружить увеличение размеров матки, не соответствующее сроку беременности или дню после 
родов, а также размягчение шейки матки. Кроме этого, можно пальпировать опухолевые образования в стенке матки, в малом тазу, во влагалище (чаще выявляются при осмотре в зеркалах). Патогномоничным признаком развития трофобластической болезни является наличие у больной текалютеиновых кист, часто очень больших размеров. В связи с этим существует риск перекручивания ножки кисты либо нарушения целостности стенки кисты с развитием клинической картины «острого живота»;

Следует обратить внимание на важность бережного осмотра больной с большими размерами матки, большими опухолевыми образованиями в матке, параметриях, стенках влагалища, с влагалищным кровотечением, тека-лютеиновыми кистами. Гинекологический осмотр в таких ситуациях должен ограничиваться наружным осмотром в зеркалах, т. к. тщательное двуручное исследование может спровоцировать разрушение обильно васкуляризованной опухоли и кровотечение, как наружное, так и внутреннее.

- пальпация живота, аускультация легких;

- оценка общих проявлений болезни: такие симптомы как слабость, головокружение, бледность кожных покровов, тахикардия, кашель, кровохарканье, одышка, головная боль, боли в животе могут иметь место при значительном распространении опухоли и длительном течении болезни и, как правило, отсутствуют на ранних стадиях.

- при наличии жалоб со стороны ЦНС (нарушение зрения, головная боль, головокружение, эпизоды потери сознания и др.) показана консультация окулиста и невролога (нейрохирурга).

\section{4. Лабораторная диагностика}

- Определение $\beta$-ХГЧ в сыворотке является ключевым в диагностике ЗТО: чувствительность этого теста при трофобластической болезни близка к $100 \%$; наличие у больной репродуктивного возраста нарушений менструального цикла и беременности в анамнезе всегда требует исключения трофобла-

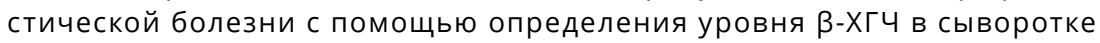

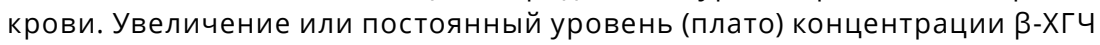
в трех последовательных анализах крови, сданных с интервалом 7 дней в течение 2 нед. (1-й, 7-й и 14-й дни), свидетельствует о развитии 3ТО;

- плацентарный лактоген является вторым обязательно исследуемым маркером, уровень которого может повышаться при трофобластической опухоли плацентарного ложа.

\section{5. Морфологическое исследование}

Морфологическое исследование является важной составляющей диагностического поиска. Исследованию подвергаются удаленные при выскабливании полости матки ткани, а также материал, полученный в результате предшествую- 
щих хирургических вмешательств. ИГХ исследование удаленных тканей имеет большое диагностическое значение при резистентности опухоли, рецидивах и редких формах ЗТО.

Морфологическое подтверждение диагноза при ЗТО не является обязательным: не следует добиваться получения диагностического материала путем повторных выскабливаний матки, т. к. это может привести к перфорации органа. Доказано, что каждое дополнительное выскабливание матки ухудшает течение болезни.

\section{6. Инструментальная диагностика}

- УзИ органов брюшной полости и малого таза, забрюшинного пространства должно выполняться в день обращения пациентки;

- $\mathrm{R-логическое} \mathrm{исследование} \mathrm{органов} \mathrm{грудной} \mathrm{полости} \mathrm{должно} \mathrm{выполняться}$ в день обращения пациентки;

- КТ органов грудной полости показана:

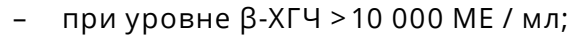

- при выявлении очагового поражения легочной ткани по данным R-логического исследования легких (для уточнения количества, размеров и локализации очагов);

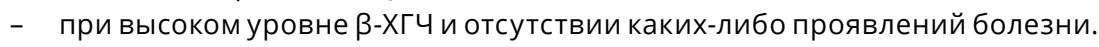

- МРТ головного мозга с контрастированием выполняется больным с метастазами в легких и / или других органах;

- ПЭТ / КТ выполняется при резистентных диссеминированных опухолях и рецидивах ЗТО.

\section{7. Критерии диагноза}

Критериями диагноза «трофобластическая неоплазия» или «ЗТО», согласно рекомендациям BO3 и FIGO 2000 г., являются:

- увеличение или постоянный уровень (плато) концентрации $\beta$-ХГЧ в трех последовательных анализах крови, сданных с интервалом 7 дней в течение 2 нед. (в 1-й, 7-й и 14-й дни) после удаления пузырного заноса;

- повышенный уровень $\beta$-ХГ через $\geq 6$ мес. после удаления пузырного заноса;

- гистологическая верификация ЗТО: хориокарцинома, опухоль плацентарного ложа, эпителиоидная трофобластическая опухоль.

\section{3. ЛЕЧЕНИЕ}

Лечение больных ЗТО должно быть начато в кратчайшие сроки: время обследования и начала лечения в специализированных отделениях по лечению ЗТО не должно превышать 48 часов. Отсрочка лечения может значительно 
ухудшить течение и прогноз болезни, особенно при диссеминированных формах опухоли.

\section{1. Лекарственное лечение}

\subsection{1. Планирование лечения злокачественных трофобластических опухолей}

Основным методом лечения ЗТО время является противоопухолевая лекарственная терапия. Стандартная ХТ позволяет достичь полного выздоровления у абсолютного большинства больных без применения дополнительных методов лечения. Успех ХТ определяется соблюдением ряда важных условий:

- лечение следует проводить только в специализированной клинике, располагающей современными возможностями диагностики и опытом успешного лечения этой категории больных;

- при отсутствии у клинициста опыта лечения ЗТО следует незамедлительно обратиться в экспертное медицинское учреждение (ФГБУ «НМИЦ онкологии им. Н.Н. Блохина» Минздрава России), это позволит сохранить женщине жизнь и репродуктивное здоровье;

- лечение должно начинаться со стандартной ХТ І линии (табл. 3), режим которой определяется принадлежностью пациентки к одной из групп риска развития резистентности опухоли; группа риска определяется по шкале FIGO (2000 г.) с учетом результатов обследования (табл. 2):

- $\quad \leq 6$ баллов соответствуют низкому риску;

- $\quad \geq 7$ баллов соответствуют высокому риску;

- пациенткам, получавшим ранее нестандартные режимы XT, после определения группы риска следует начать стандартную ХТ;

- кровотечение из опухоли не является противопоказанием к началу ХТ, которую необходимо проводить одновременно с интенсивной гемостатической терапией;

- неконтролируемое маточное кровотечение может быть купировано с помощью селективной эмболизации маточных артерий;

Больным с верифицированными редкими трофобластическими опухолями (трофобластическая опухоль плацентарного ложа, эпителиоидная трофобластическая опухоль) лечение следует проводить без учета суммы баллов по шкале режимом ЕMA-EP (табл. 4) и только в условиях экспертной клиники. 
Таблица 3. Рекомендуемые режимы химиотерапии I линии злокачественных трофобластических опухолей ${ }^{1}$

\begin{tabular}{|l|l|}
\hline Низкий риск & Высокий риск \\
\hline Mtх/FA: & ЕМА-СО: \\
метотрексат 50 мг в/м в 1-й, 3-й,5-й,7-й дни & этопозид 100 мг/м² в/в в 1-й и 2-й дни, \\
кальция фолинат 6 мг в/м во 2-й, 4-й, & дактиномицин 500 мкг в/в в 1-й и 2-й дни, \\
6-й,8-й дни, через 30 часов после введения & метотрексат 100 мг/ м² в/в струйно с последующей 12-часо- \\
метотрексата; & вой инфузией в дозе 200 мг/м² в 1-й день, \\
повторные курсы - с 15-го дня от начала & кальция фолинат 15 мг в/м через 24 часа от начала \\
предыдущего курса & введения метотрексата, затем - каждые 12 часов, всего - \\
& 4 дозы, \\
& циклофосфамид 600 мг/м² в/в в 8-й день, \\
& винкристин 1 мг/м² в/в струйно в 8-й день; \\
& повторные курсы - с 15-го дня от начала предыдущего курса \\
\hline
\end{tabular}

1 Лечение проводится до нормализации уровня $\beta$-ХГЧ, затем - дополнительно 3 консолидирующих курса в аналогичном режиме (для больных с IV cmaдией - 4 курса)

\subsection{2. Контроль эффективности и продолжительность XT}

Оценка клинического эффекта производится по уровню $\beta$-ХГЧ, который должен определяться:

- в группе низкого риска - в 0-й (до начала лечения) и 14-й дни, далее перед началом каждого курса ХT;

- в группе высокого риска - в 0-й (до начала лечения), 7-й и 14-й дни, т. е. еженедельно.

Об эффективности лечения свидетельствует прогрессивное снижение уровня $\beta$-ХГЧ. Лечение проводится до нормализации уровня маркера, после чего проводятся 3 курса консолидирующей XT (для больных с IV стадией - 4 курса) с использованием этого же режима. Лечение может быть прекращено раньше при появлении признаков резистентности, к которым относятся:

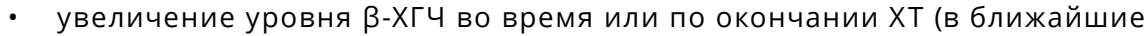
6 мес.), зафиксированное в трех последовательных анализах крови, сданных в течение 10 дней;

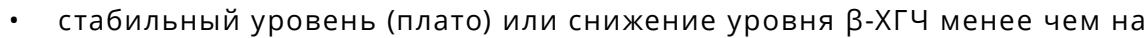
$10 \%$, зафиксированное в трех последовательных анализах крови, сданных в течение 10 дней.

\subsection{3. Тактика при формировании резистентности опухоли.}

Прогноз при резистентности к ХТ І линии определяется эффективностью XТ II линии, в связи с этим обследование и лечение больных этой категории должно проводиться только в специализированной клинике, имеющей соответствующий опыт. Для планирования лечения необходимо повторное обследование в соответствии с алгоритмом с последующим определением 
категории риска. В группе исходно низкого риска проводится пересчет суммы баллов по шкале FIGO (2000 г.) с учетом результатов обследования (табл. 2):

- $\quad \leq 6$ баллов соответствуют низкому риску; в этой группе проводится ХТ II линии в режиме дактиномицин в 1-5-й дни (табл. 4);

- $\quad 27$ баллов соответствуют высокому риску; в этой группе в качестве ХТ II линии назначается режим ЕМА-EP (табл. 4).

Проведение XT II линии в группе больных с высоким риском требует соответствующей квалификации персонала и должно проводиться только в специализированной клинике, имеющей соответствующий опыт. Необходимо незамедлительно обратиться в экспертное медицинское учреждение (ФГБУ «НМИЦ онкологии им. Н.Н. Блохина» Минздрава России). В табл. 4 представлены рекомендуемые режимы ХТ ІІ линии для резистентных ЗТО.

Таблица 4. Рекомендуемые режимы химиотерапии II линии при резистентных злокачественных трофобластических опухолях ${ }^{1}$

\begin{tabular}{|c|c|}
\hline $\begin{array}{l}\text { Низкий риск } \\
\text { резистентности }\end{array}$ & Высокий риск резистентности \\
\hline $\begin{array}{l}\text { Дактиномицин } \\
500 \text { мкг в/в струйно } \\
\text { с 1-го по 5-й дни } \\
\text { (с противорвотной } \\
\text { терапией); } \\
\text { повторные курсы - } \\
\text { с 15-го дня от начала } \\
\text { предыдущего курса }\end{array}$ & 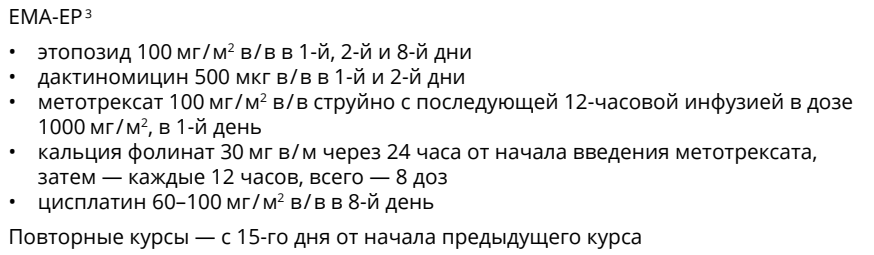 \\
\hline ЕМА-СО (табл. 3) ${ }^{2}$ & 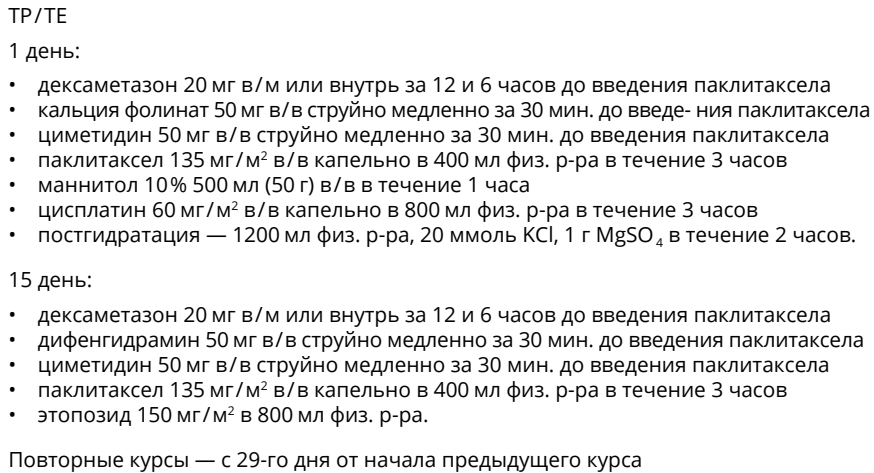 \\
\hline
\end{tabular}

1 Лечение проводится до нормализации уровня $\beta$-ХГЧ, затем - дополнительно 3 консолидирующих курса в аналогичном режиме (для больных с IVcmaдией - 4 курса).

2 Лечение в 1-й и 2-й дни должно сопровождаться обязательной гидратацией (не менее 2 л физ. p-ра), трансфузией раствора гидрокарбоната натрия и противорвотной терапией.

3 Лечение в 1-й, 2-й и 8-й дни должно сопровождаться обязательной гидратацией (не менее 2 л физ. р-ра), трансфузией раствора гидрокарбоната натрия и противорвотной терапией. 
Оценка эффективности в процессе XT II линии аналогична таковой для І линии (см. раздел 3.1.2.).

При развитии множественной лекарственной резистентности (к XTII линии) у больных с высоким риском следует незамедлительно направить пациентку в экспертный трофобластический центр для определения дальнейшей тактики лечения. Отсутствие опыта у клиницистов может значительно ухудшить прогноз заболевания.

\section{2. Хирургическое лечение}

Показания к хирургическому лечению:

- кровотечение из первичной опухоли или метастаза, угрожающее жизни больной;

- перфорация опухолью стенки матки;

- $\quad$ резистентность первичной опухоли к лекарственной терапии (неэффективность стандартной XТ I и II линий) при отсутствии отдаленных метастазов;

- резистентность солитарных метастазов опухоли (при отсутствии первичной опухоли и метастазов в других органах) при наличии возможности одномоментного удаления всех резистентных очагов и проведения ХТ после операции.

Хирургическое лечение при резистентности трофобластической опухоли следует выполнять только в условиях экспертного трофобластического центра. Оптимальными объемами хирургических вмешательств являются:

- органосохраняющая гистеротомия с иссечением опухоли в пределах здоровых тканей у больных репродуктивного возраста;

- резекция пораженного органа с резистентным метастазом в пределах здоровых тканей (возможно - эндоскопическим путем);

- восстановление целостности матки, ушивание перфорационного отверстия, остановка кровотечения путем перевязки маточных артерий с целью сохранения органа.

\section{3. Лучевая терапия}

Основным показанием для ЛТ при ЗТО являются метастазы в головном мозге. Оптимальным является дистанционное облучение всего головного мозга, РОД 2 Гр, СОД 30-40 Гр. Поскольку абсолютное большинство больных с метастазами ЗТО в головном мозге излечиваются только с помощью интенсивной ХТ, решение вопроса о необходимости лт должно приниматься только с участием специалиста экспертного трофобластического центра. Стереотаксическая Лт резистентных метастазов ЗТО выполняется в специализированной клинике после консилиума ведущих специалистов в данной области. 


\section{4. ПРОФИЛАКТИКА}

Специфической профилактики не существует. Для профилактики рецидивов ЗТО рекомендуется:

- обязательное проведение консолидирующих циклов ХТ после нормали-

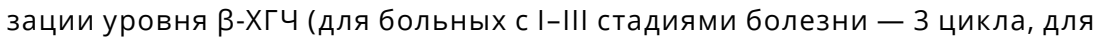
больных с IV стадией - 4 цикла той же XT);

- контрацепция после окончания лечения по поводу ЗТО в течение не менее 1 года для больных с I-III стадией, в течение 2 лет - для больных c IV стадией.

\section{5. ДИСПАНСЕРНОЕ НАБЛЮДЕНИЕ}

Диспансерному наблюдению подлежат все пациентки. Основным крите-

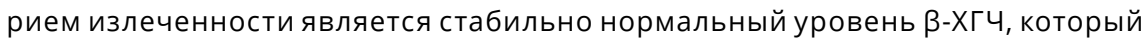
необходимо контролировать:

- после удаления пузырного заноса - еженедельно до нормализации, за-

тем - ежемесячно в течение 1 года;

- после окончания лечения по поводу ЗТО:

- первые 3 мес.- 2 раза в мес.;

- первый год - ежемесячно;

- второй год - 1 раз в 2 мес.;

- третий год - 1 раз в 3-4 мес.

Определение сывороточного уровня $\beta$-ХГЧ является обязательным у больных, перенесших пузырный занос (независимо от срока давности), в случае выявления у них каких-либо новообразований в легких либо других паренхиматозных органах.

Обязательным является ведение менограммы пациенткой в течение не менее 3-х лет после окончания лечения 3ТО. 